\title{
Analysis on the Movement of Slungshot and Impact Force
}

\author{
Wenjing Lu1, Yan Zhang2,3 \\ ${ }^{1}$ Middle School Attached to University of Beijing Jiaotong, Beijing, China \\ ${ }^{2}$ Department of Engineering Sciences, University of Chinese Academy of Sciences, Beijing, China \\ ${ }^{3}$ Institute of Mechanics, Chinese Academy of Sciences, Beijing, China \\ Email: 915347208@qq.com
}

How to cite this paper: Lu, W.J. and Zhang, Y. (2017) Analysis on the Movement of Slungshot and Impact Force. Engineering, 9, 874-879.

https://doi.org/10.4236/eng.2017.910052

Received: September 4, 2017

Accepted: October 16, 2017

Published: October 19, 2017

Copyright ( 2017 by authors and Scientific Research Publishing Inc. This work is licensed under the Creative Commons Attribution International License (CC BY 4.0).

http://creativecommons.org/licenses/by/4.0/

\begin{abstract}
Slungshots can be induced by earthquake, causing heavy damage to people. Preliminary study of this problem was carried out. Firstly, a mathematical model for describing the movement of slungshot was presented based on the theories of rigid body kinematics and aerodynamics. The effects of air drag and the rotation of rock were considered. Secondly, the trail of movement and the velocity were studied based on the presented model, taking the slungshot recorded in the 5.12 earthquake in the Yingxiu County as example. Thirdly, the impact force of the slungshot on the ground was studied. This study provides a reference for the forecast and prevention of the slungshot hazard.
\end{abstract}

\section{Keywords}

Mathematical Model for Slungshot, Movement Trail, Impact Force

\section{Introduction}

Kinds of hazards such as landslide, rockfall and slungshot can be caused by earthquake. Slungshot, a large stone suddenly collapses and flies away from a slope, is a kind of common mountain hazard which can be observed on high and steep slopes. Slungshot can induce the damage of highway, railway and houses. The scale of slungshot can be from several miters to dozen meters and the speed can be tens of meters per second. That means, the destructive power is strong [1] [2]. For example, heavy loss was caused by the slungshot during the earthquake happened in 2018 in Wenchuan, China [3]. It can not only cause significant casualties during earthquake, but also threaten the rescuers and traffic. According to the site investigation, a large stone weighted $3 \times 10^{5} \mathrm{~kg}$ was ejected from the slope adjacent to the express way during earthquake in Yingxiu county, Wen- 
chuang, China (Figure 1). The horizontal flight distance is $\mathrm{s}=61.9 \mathrm{~m}$ and the vertical distance is $\mathrm{Hv}=64.4 \mathrm{~m}$ (Figure 2) [4]. The flight path and impact force determine the loss degree caused by the slungshot.

In this paper, the movement characteristics of slungshot (flight path and touchdown velocity) and the impact force are analyzed. The results can be referenced in the design of prevention engineering for slungshot.

\section{Mathematical Model and Analysis}

Considering a stone located at a slope is spherical and rigid for the convenience of analysis (Figure 2). The initial translation movement is caused by earthquake and not in horizontal direction. Rotation movement is induced by the rolling of the stone before it breaks away from the slope.

To understand the movement of stone in the air, the knowledge of rigid motion and aerodynamics must be clear. The flight path is determined by the gravity, air resistance and the force caused by rotation. As we all know, a transverse force will occur in the direction vertical to the plane formed by the vectors of rotation angular speed and translation speed when the vector of rotation angular

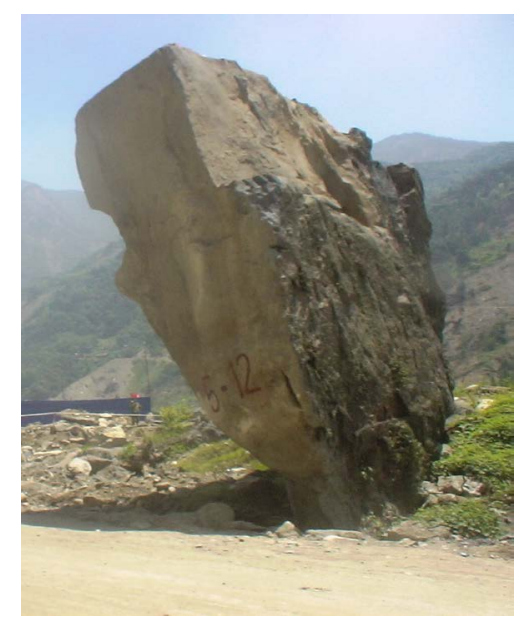

Figure 1. Slungshot at Yingxiu, Wenchuan.

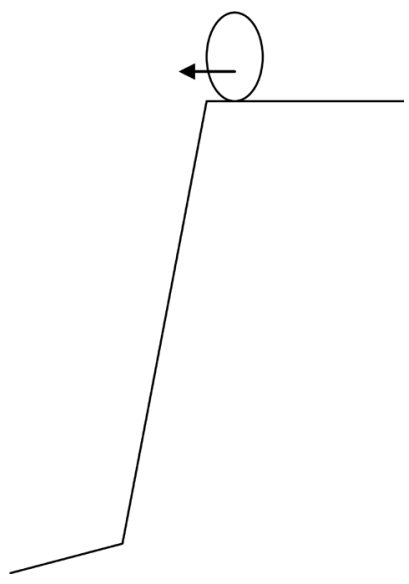

Figure 2. Sketch of problem. 
speed is not coincided. The flight path will deflect under this transverse force, which is called Magnus effect.

During the translation movement with rotation movement of an object, because of the air viscosity, the air near the object will adhere to and move with the object, forming circular current surrounding the object. The superimposition of translation movement and the circular current leads to the differences of the air velocity at the two sides of the object. The pressure at the side with larger speed is smaller than that with smaller speed. This force is called Magnus force and always perpendicular to the direction of translation movement. In other words, this force only changes the direction of movement. Generally, an object subjects Magnus force besides gravity and air resistance when it moves with rotation. The Magnus force for a sphere can be computed by the following equation: $\mathrm{F}_{2}=$ $8 \pi \rho \omega a^{3} v / 3$, in which $\rho$ is the density, $a$ is the radium of sphere, $v$ is the speed of translation movement, $\omega$ is the angular speed of rotation [5] [6].

The air resistance is determined by the relative speed and shape of the object. The larger the relative speed is, the larger the resistance is. The air resistance can be expressed as $\mathrm{F}_{1}=\chi V^{2}$, in which $\chi$ is the coefficient of resistance, the direction is always opposite with the translation movement [5]. For example, if a sphere moves inclined upwards from the right to the left, meaning the air flows inclined downwards from the left to the right, and meanwhile the sphere rotated clockwise in the vertical plane, the sphere will suffer the Magnus force inclined upwards. Considering the downward gravity and the air resistance opposite to the translation movement, the motion equation for the sphere can be presented as follows according to the Newton's second law:

$$
\begin{gathered}
m \frac{\mathrm{d} V}{\mathrm{~d} t}=F_{1}=-\chi V^{2}-m g \sin \theta \\
m \frac{V^{2}}{R}=m g \cos \theta-F_{2}
\end{gathered}
$$

in which $m$ is the mass, $g$ is the gravity acceleration, $\theta$ is the initial angle between the velocity and the horizontal line. It can be seen that the motion characteristics of slungshot are determined mainly by the sphere's mass, air resistance, rotational angular speed, initial ejection angle etc. If the directions of translation movement and rotation movement change, the signs of the terms in the right of the above equations must be change accordingly.

If the speed of the translation movement is small and rotation is slow, the air resistance and the Magnus force can be both neglected. In this case the motion Equations ((1) and (2)) can be simplified. Letting the initial velocity of translation movement be $V_{0}, x$ and $y$ are respectively the displacements in horizontal and vertical directions, the motion path can be described as follows:

$$
\begin{gathered}
x=V_{0} t \cos \theta \\
y=V_{0} t \sin \theta-0.5 g t^{2}
\end{gathered}
$$

Instituting Equation (3) into Equation (4), the parapolic type motion path is 
obtained:

$$
y=x \tan \theta-\frac{g x^{2}}{2 V_{0}^{2} \cos ^{2} \theta}
$$

Rewriting Equation (5), the vertex form of Equation (5) can be given

$$
y=-\frac{g}{2 V_{0}^{2} \cos ^{2} \alpha}\left(x-\frac{V_{0}^{2} \sin (2 \alpha)}{2 g}\right)^{2}+\frac{V_{0}^{2} \sin ^{2} \alpha}{2 g}
$$

The theoretical solutions of Equations ((1) and (2)) are difficult to be obtained. But one can compute the motion path and velocity parameters with these two equations. If the motion path is known, the initial velocity, the angle and rotational angular speed can be inversely computed. In the case of small translation movement and rotation movement, Equations (3) (6) are enough to do the same thing. Figure 3 shows the motion path according to Equations ((1) and (2)) and the data of the slungshot in Yingxiu county (described in the first paragraph.). It can be seen that the motion path is not parabolic. The motion path changes with the initial translation speed, initial ejection angle and resistance coefficient and rotational angular speed.

\section{Impact Force of Slungshot with the Ground}

A slungshot will cause large impact force when it contacts a structure or the ground. This type of force is one of the main loads considered in the design of open cut tunnel, shed-tunnel and rock retaining wall [7]. The impact of a slungshot with ground or structures is related with elasto-plastic deformation. So the computation on the impact force is complex. Empirical formula on the impact force is given in the standards of road and railway in China [8] [9] and foreign recommended methods such as Japan Highway Public Corporation method [10].

According to the standard for highway subgrades (JTJ13-95), the impact force induced by slungshot is computed by the following formula:

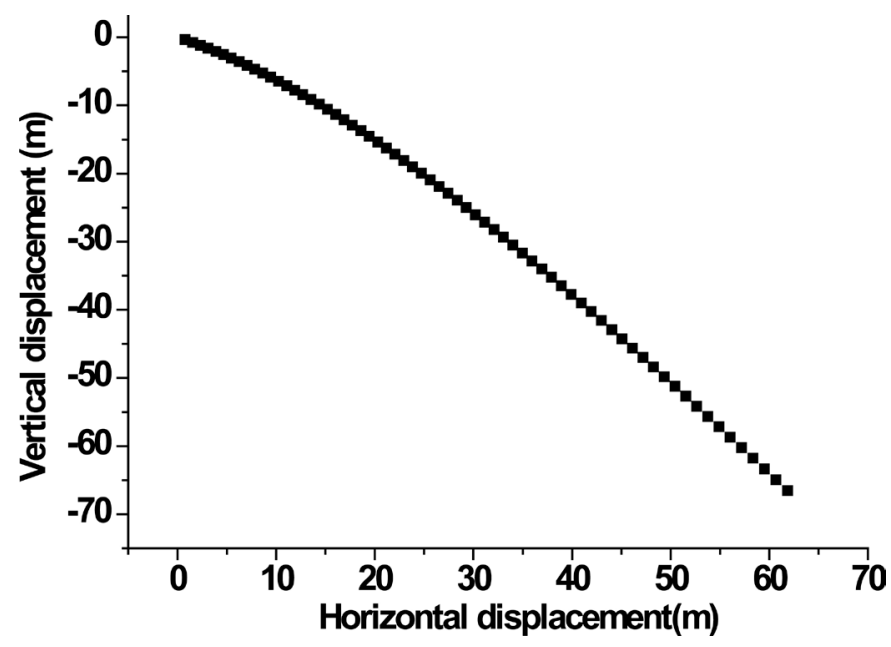

Figure 3. Trail of slungshot. 


$$
\begin{gathered}
P=P(Z) F=2 \gamma Z\left[2 \tan ^{4}\left(45^{\circ}+\frac{\phi}{2}\right)-1\right] F \\
Z=V_{R} \sqrt{\frac{Q}{2 g \gamma F}} \times \sqrt{\frac{1}{2 \tan ^{4}\left(45^{\circ}+\frac{\phi}{2}\right)-1}}
\end{gathered}
$$

in which $\mathrm{P}$ is the impact force caused by slungshot $(\mathrm{kN}), P(Z)$ is the unit resistance of ground subjected by the slungshot $(\mathrm{kPa}), Z$ is the depth the slungshot enters into the ground $(\mathrm{m}), V_{R}$ is the instantaneous speed of slungshot when it touches the ground $(\mathrm{m} / \mathrm{s}), Q$ is the gravity of the slungshot $(\mathrm{kN}), \gamma$ is the density of ground $\left(\mathrm{kN} / \mathrm{m}^{3}\right), \mathrm{g}$ is the acceleration of gravity, $\varphi$ is the internal friction angle of ground, $F$ is the sectional area of the slungshot's equivalent sphere volume $\left(\mathrm{m}^{2}\right)$.

We will take the slungshot in the Yingxiu county as example in this section. The instantaneous speed of the slungshot when touching the ground is $40 \mathrm{~m} / \mathrm{s}$. The density and internal friction angle of ground are $20 \mathrm{kN} / \mathrm{m}^{3}$ and $30^{\circ} \mathrm{m}$ respectively. The rock's sectional area of equivalent sphere volume is $28.26 \mathrm{~m}^{2}$. The weight of the rock is $3000 \mathrm{kN}$. According to Equations ((7) and (8)), the impact force is $97,667 \mathrm{kN}$.

According to the methods given by the "Manual of railway engineering design: tunnel" (revised version) [5]. This method is based on the impulse theorem. The formula for impact force is:

$$
\begin{gathered}
p=\frac{Q V_{0}}{g t} \\
t=\frac{2 h}{c} \\
c=\sqrt{\frac{1-v}{(1+v)(1-2 v)} \frac{E}{\rho}}
\end{gathered}
$$

in which $P$ is the impact force $(\mathrm{kN}), Q$ is the weight of rock $(\mathrm{kN}), V_{0}$ is the instantaneous speed of rock touching the ground $(\mathrm{m} / \mathrm{s}), t$ is the duration of impact (s), $h$ is the height of the ground $(\mathrm{m}), c$ is the speed of compressional wave in the ground $(\mathrm{m} / \mathrm{s}), v$ is the Poisson's ratio, $E$ is the resilient modulus $(\mathrm{kPa}), \rho$ is the density of ground.

We still take the slungshot in the Yingxiu county as example in this section. The resilient modulus of ground is $5 \times 10^{4} \mathrm{kPa}$. The Poisson's ratio is 0.3 . The height of ground is $10 \mathrm{~m}$. The other parameters are the same as before. The impact force is $110,070 \mathrm{kN}$ by Equations (9)-(11). The relative error of the result computed by Equations (9)-(11) is $11 \%$ compared with that by Equations ((7) and (8)). The real impact force can be thought as close to these two values.

\section{Conclusions}

This paper presents a motion model for slungshot based on the Newton's second 
law. The air resistance and Magnus effects are considered in this model. It is shown that the motion characteristics of the slungshot are determined by the weight of the rock, air resistance, rotational angular speed, translation motion, initial ejection speed and angle.

The motion path and the instantaneous speed of rock touching ground are analyzed according to the data of the slungshot happened in Yingxiu county in the 5.12 earthquake in 2008 .

By the computed instantaneous speed of rock and related formulas for impact force, the impact force is evaluated. This study can be referenced by the analysis of motion and prevention design of slungshot.

\section{References}

[1] He, S.M., Wang, D.P., Wu, Y. and Ou, Y.C.H. (2014) Formation Mechanism and Key Prevention Technology of Rockfall. Chinese Journal of Nature, 36, 336-345. (In Chinese )

[2] Alejano, L., Stockhausen, H., Alonso, E., et al. (2008) ROFRAQ: A Statistics-Based Empirical Method for Assessing Accident Risk from Rockfalls in Quarries. International Journal of Rock Mechanics and Mining Sciences, 45, 1252-1272. https://doi.org/10.1016/j.ijrmms.2008.01.003

[3] Cui, P., Wei, F.Q., He, S.M., et al. (2008) Mountain Disasters Induced by the Earthquake of May 12 in Wenchuan and Disasters Mitigation. Journal of Mountain Science, 26, 280-282. (In Chinese )

[4] Xu, Q. and Huang, R.Q. (2008) Kinetics Characteristics of Large Landslides Triggered by May $12^{\text {th }}$ Wenchuan Earthquake. Journal of Engineering Geology, 16, 721729. (In Chinese)

[5] Wu, W.Y. (1982) Fluid Mechanics. Beijing University Press, Beijing. (In Chinese )

[6] Ye, T.L., Lu, X.B., Cui, P. and Zhang, X.H. (2011) Initial Study on the Movement of Slungshot during Earthquake. Chinese Journal of Underground Space and Engineering, 7, 1780-1791. (In Chinese )

[7] Dorren, L. (2003) A Review of Rockfall Mechanics and Modeling Approaches. Progress in Physical Geography, 27, 69-87. https://doi.org/10.1191/0309133303pp359ra

[8] Ye, S.Q., Chen, H.K. and Tang, H.M. (2010) Comparative Research on Impact Force Calculation Methods for Rockfalls. Hydrogeology \& Engineering Geology, 37, 59-64. (In Chinese )

[9] Second Railway Survey and Design Institute, China, Technical Manual of Railway Engineering Design·Tunnel. China Railway Publishing House, Beijing, 141-191.

[10] Kawahara, S. and Muro, T. (2006) Effects of Dry Density and Thickness of Sandy Soil on Impact Response Due to Rockfall. Journal of Terramechanics, 43, 329-340. https://doi.org/10.1016/j.jterra.2005.05.009 